\title{
VIVÊNCIAS PESSOAIS E FAMILIARES DE HOMOSSEXUAIS FEMININAS
}

\author{
Yáskara Arrial Palma \\ Daniela Centenaro Levandowski
}

\begin{abstract}
RESUMO. O presente trabalho, teve como objetivo descrever as vivências pessoais e familiares de homossexuais femininas. Foram entrevistadas seis mulheres, residentes em Caxias do Sul e região, de 22 a 33 anos, cujos familiares conheciam sua orientação sexual. Todas eram solteiras e de nível socioeconômico médio, e exerciam alguma atividade profissional. Uma análise de conteúdo qualitativa das entrevistas gerou diversas categorias e subcategorias temáticas. Em geral, a homossexualidade foi considerada normal/natural, uma situação que trouxe felicidade para as participantes, apesar dos preconceitos enfrentados. Na percepção delas, a reação dos familiares quando da descoberta da sua orientação sexual foi negativa, tendo melhorado ao longo do tempo em alguns casos. Tais achados revelaram uma mudança social na forma de pensar e agir diante da homossexualidade feminina, porém ainda lenta e gradual. Ficou evidenciada a necessidade de atuação da psicologia através de programas de atendimento às famílias e às homossexuais.
\end{abstract}

Palavras-chave: homossexualidade feminina, vivências pessoais e familiares.

\section{LESBIANS' PERSONAL AND FAMILY EXPERIENCES}

\begin{abstract}
The personal and familiar experiences of female homosexuals are provided. Six females (22 to 33 years old) from Caxias do Sul RS Brazil, and neighboring region, whose family members were aware of their sexual orientation, were interviewed. Females were single, middle-class socio-economic level, with professional activity. A qualitative content analysis of the interviews produced several thematic categories and subcategories. Homosexuality, as a rule, considered normal and natural, brought happiness to participants in spite of the bias they had to face. From their point of view, their families' first reaction to their sexual orientation was negative, although, in some cases, it improved with the passing of time. Results revealed a social change, albeit slow and gradual, in the way of thinking and acting towards female homosexuality. The need for psychological intervention through programs for families and for homosexual subjects is required.
\end{abstract}

Key words: Female homosexuality, personal and familiar experiences.

\section{VIVENCIAS PERSONALES Y FAMILIARES DE HOMOSEXUALES FEMENINAS}

RESUMEN. Ese trabajo objetivó describir las vivencias personales y familiares de homosexuales femeninas. Seis mujeres (22 a 33 años), de Caxias del Sur y región, cuyos familiares conocían su orientación sexual, fueron entrevistadas. Todas eran solteras, de nivel socio-económico medio y ejercían alguna actividad profesional. Análisis de contenido cualitativa de las entrevistas generó diversas categorías y subcategorías temáticas. En general, la homosexualidad fue considerada normal/natural, una condición que trajo felicidad, a pesar de los prejuicios enfrentados. Las participantes consideraron negativa la reacción de los familiares frente a la descubierta de su orientación sexual, lo que ha mejorado a lo largo del tiempo en algunos casos. Tales resultados revelaron un cambio social en la manera de pensar y actuar delante de la homosexualidad femenina, sin embargo aún lenta y gradual. Se quedó evidenciada la necesidad de actuación de la psicología a través de programas para las mujeres y sus familiares.

Palabras-clave: Homosexualidad femenina, vivencias personales y familiares.

As relações sexuais entre pessoas do mesmo sexo sempre existiram, desde as sociedades primitivas, em todas as culturas. De fato, os primeiros relatos acerca disso apareceram por volta da terceira dinastia egípcia,

* Psicóloga na Associação de Pais e Amigos dos Excepcionais (APAE) - Núcleo Feliz.

\# Psicóloga. Doutora em Psicologia do Desenvolvimento. Professora Assistente do Programa de Pós-Graduação em Psicologia Mestrado Acadêmico, da Universidade do Vale do Rio dos Sinos-Unisinos. 
cerca de 2.500 anos A. C. (Miranda, 2001). Em algumas civilizações antigas, essas relações, principalmente entre homens adultos e jovens, só eram repudiadas quando ameaçavam subverter a hierarquia social da época (Lacerda, Pereira \& Camino, 2002).

Tal condição foi interpretada, admitida e explicada de diferentes formas ao longo do tempo. Foi somente a partir da tradição judaico-cristã que essa prática passou a ser concebida como pecaminosa. Somando-se a isso, a partir do século XIX a medicina definiu a homossexualidade como uma doença fisiológica (Miranda, 2001), e no início do século XX introduziu-se uma visão psicológica do fenômeno, que considerou tal prática como um desvio no desenvolvimento da sexualidade (Freud, 1905/1976, p. 129). Já em 1917, o autor definiu os homossexuais como "uma variedade especial da espécie humana, um terceiro sexo que tem o direito de se situar em pé de igualdade com os outros dois" (Freud, 1917/2007, p. 46).

Justamente em função disso, a denominação inicial de "homossexualismo" serviu para indicar um desvio ou anormalidade, em função do sufixo ISMO, que traria a imagem de doença (Laurenti, 1984). Em 1948 esse quadro "psicopatológico" apareceu na $6^{\text {a }}$ revisão da Classificação Internacional de Doenças (CID), na categoria Personalidade Patológica. Em 1973 a Associação Psiquiátrica Americana considerou que a homossexualidade não era uma doença; dois anos mais tarde, a Associação Americana de Psicologia (APA) chegou à mesma conclusão e, em 1987, o DSM-III já não contemplava a homossexualidade como uma parafilia (Matias, 2007).

Em nosso país, foi apenas na década de 80 que o Conselho Federal de Medicina tornou sem efeito o código 302.0 da Classificação Internacional de Doenças (CID), deixando de considerar a homossexualidade como uma categoria de desvios e transtornos sexuais. Já o Conselho Federal de Psicologia pronunciou-se oficialmente em 1999, por meio da Resolução CFP 01/99, definindo como antiética a postura de psicólogos que tratam a homossexualidade como desvio comportamental ou doença. No cenário mundial, nessa mesma época, a Organização Mundial de Saúde também repudiou a conotação de doença dessa prática afetiva e sexual (Ferreira, 2007).

No Brasil, Mott (1987) pontuou que, com a chegada dos colonizadores portugueses, as práticas homossexuais se ampliaram e diversificaram, pois já existiam entre os indígenas. Contudo, a partir de 1591, a Inquisição começou sua atuação, perseguindo homossexuais femininas, situação que se perpetuou até o século XVIII, período em que a lesbianidade apareceu nos palácios imperiais. $\mathrm{O}$ autor comenta que a partir da segunda metade do século XIX o amor entre mulheres passou a ser encontrado em algumas referências bibliográficas, tais como no livro "Atentados ao Pudor" (1894) de Viveiros Castro (citado por, Mott, 2001), mas somente no século XX surgiu a primeira publicação nacional lésbica, intitulada ChanacomChana, que começou como um boletim e transformou-se em um jornal, hoje inexistente $^{1}$ (Mesquita, 2004).

Conforme Góis (2003), foi a epidemia da aids que acelerou os estudos sobre a homossexualidade no Brasil durante os anos noventa, com a ampliação do debate público sobre a sexualidade humana. O inconveniente disso foi o fato de o tema ter ficado estreitamente ligado ao campo dos processos saúdedoença. Outro fator que contribuiu para a maior visibilidade da lesbianidade, na visão de Borges (2005), foi o movimento feminista e, junto com ele, a mídia, especialmente nas décadas de setenta e oitenta. Dos anos noventa em diante aumentou o número de mulheres autodeclaradas lésbicas e feministas, que pressionaram o movimento para a discussão dos direitos sexuais. A mídia, por sua vez, colaborou para a construção e a circulação de repertórios sobre o tema, atuando como mediadora no seu acesso e na sua legitimação para uma grande variedade de destinatários.

Com o advento dos estudos feministas, surgiram também os estudos relacionados ao gênero, entendido como algo que se constitui nos diferentes tempos e espaços sociais (Victora \& Knauth, 2004). Destarte passou-se a questionar a existência de um comportamento essencialmente masculino ou feminino, ou seja, a visão binária do mundo e das relações de gênero, identificando o masculino e o feminino como termos opostos, ainda que complementares (Torrão Filho, 2005), pois a própria concepção de um "masculino" se define em relação a um "feminino", e vice-versa.

Essa visão binária, que se opõe masculino/feminino, forte/fraco, ativo/passivo, dominante/dominado, traz em seu bojo uma concepção das relações de gênero como fundadas em categorizações presentes em toda a ordem social, permitindo compreender a posição das mulheres como subordinadas, além da relação entre sexualidade e poder (Anjos, 2000). Conforme essa ótica, o feminino

\footnotetext{
Disponível em http://www.jornal.uem.br/cms/index.php? option=com_content\&task=view\&id=53\&Itemid=2>, acesso em 26 de dezembro de 2007.
} 
seria uma ameaça à heterossexualidade masculina; a masculinidade seria interditada à mulher, sendo que as mulheres homossexuais usurpariam um poder que não lhes pertence (Torrão Filho, 2005).

A lesbianidade foi definida por Garcia (2003) ora como amor entre mulheres, ora como uma prática sexual destas entre si. De fato, conforme Mott (1987), a maioria das lésbicas não persegue o prazer sexual como finalidade única na relação com a companheira; seus objetivos são níveis profundos de comunicação, ternura, carinho e delicadeza. Então, a amizade é que se torna sexualizada, pois a relação sexual nasce de um sentimento profundo que tem por base o amor.

Da mesma forma, Heilborn (1992) apontou que o casal de mulheres seria marcado por um intenso companheirismo, com forte ênfase no apoio psicológico mútuo, e que a sexualidade não encontra entre as lésbicas a mesma importância que tem entre os gays, pois a escolha das parceiras, mesmo eventuais, não se efetiva em função da atração sexual, e sim, do amor. Por isso, essas relações também teriam uma duração maior em comparação à dos relacionamentos homossexuais masculinos. Marvin e Miller (2002) afirmam que os casais de lésbicas são vistos como semelhantes aos casais heterossexuais, e, se comparados aos homossexuais masculinos, apresentam de forma mais intensa a homogamia social presente nos casais igualitários.

Nesse sentido, cabe destacar a grande incidência de lésbicas que tiveram algum tipo de relacionamento heterossexual prévio à opção pela prática sexual homoerótica. Isso ocorre, segundo Fairchild e Hayward (1996), em função de essas mulheres não assumirem seus verdadeiros desejos sexuais, percebidos desde a infância, muitas vezes a partir das diferenças entre elas e suas amigas e colegas.

Em relação a isso, Mott (1987) afirma que são poucas as homossexuais que conseguem a maturidade da auto-aceitação e revelam a sua orientação sexual para familiares ou colegas. Por outro lado, a grande maioria das mães que têm filhas homossexuais parece esperar uma mudança nessa orientação sexual. Com isso, acaba predominando a intolerância e o inconformismo, constituindo-se a família, para a grande maioria de lésbicas, a principal preocupação, seja como fonte de repressão, seja como cobradora de compromissos sociais heterossexuais. Desse modo, fica evidente que as famílias de origem, na maior parte das vezes, operam a partir de uma crença de que todos os filhos serão heterossexuais e crescerão seguindo estilos de vida e vivências desse tipo (Sanders, 1994). De fato, arquivos do Grupo Gay da Bahia trazem inúmeros registros de filhos e filhas que sofreram inúmeras agressões físicas por parte dos pais, quando esses descobriram sua homossexualidade (Mott, 2003).

Experiências de imposição, mal-entendidos, isolamento, solidão e auto-recriminação podem continuar acontecendo e tornarem-se piores se não houver um esclarecimento das famílias em relação às suas expectativas acerca dos filhos e desses em relação a seus pais, alcançando-se uma aceitação mútua e um novo tipo de relacionamento; até mesmo porque, aceitar de forma completa as expectativas e demandas sociais e familiares, para manter o amor em segredo, pode limitar a vida do indivíduo, gerando um isolamento pessoal muitas vezes opressivo (Sanders, 1994).

A partir das idéias expostas, constata-se que a homossexualidade feminina se encontra em um processo de maior visibilidade, porém ainda permeado de medos, preconceitos e dificuldades, tanto da própria mulher como de seus familiares. Nesse sentido, o presente estudo teve como objetivo descrever as vivências pessoais e familiares, em relação à homossexualidade, de mulheres que se relacionam afetiva e sexualmente com outras mulheres.

\section{MÉTODO}

\section{Participantes}

Participaram da pesquisa seis mulheres homossexuais, com idades variando entre 22 e 33 anos, predominantemente solteiras e com nível de escolaridade médio a superior incompleto. Todas elas exerciam alguma atividade profissional, residiam em Caxias do Sul e região e se enquadravam em um nível socioeconômico médio. A Tabela 01 apresenta de modo mais detalhado os dados demográficos das participantes.

Tabela 1. Dados Demográficos das Participantes do Estudo.

\begin{tabular}{rcccc}
\hline Participantes & Idade (anos) & Estado Civil & Escolaridade & Ocupação Atual \\
P1 & 25 & Solteira & Ensino Médio & Vendedora \\
P2 & 32 & Separada & Ensino Médio & Auxiliar de Produção \\
P3 & 33 & Separada & Ensino Superior incompleto & Estudante e Técnica de Enfermagem \\
P4 & 28 & Solteira & Ensino Médio & Assistente de RH \\
P5 & 22 & Solteira & Ensino Superior incompleto & Estudante e secretária \\
P6 & 23 & Solteira & Ensino Superior incompleto & Estudante e instrutora de academia \\
\hline
\end{tabular}




\section{Delineamento, procedimentos e instrumentos}

O presente estudo teve um caráter qualitativo. A localização das participantes se deu através de uma rede de relações das autoras do artigo. Tais pessoas entraram em contato com mulheres que haviam revelado a sua orientação homossexual para a família. Obteve-se, então, a indicação de diversos nomes. Após receber a indicação das participantes, foi realizado contato telefônico com elas, explicando-se novamente os objetivos da pesquisa e realizando-se um convite para a participação. Acredita-se que esse procedimento tenha facilitado a coleta de dados, pois nenhuma das mulheres contatadas se recusou a colaborar no estudo. A partir da aceitação, procedeuse ao agendamento de um horário e local para a realização de uma entrevista.

$\mathrm{O}$ instrumento utilizado foi uma entrevista de caráter semi-estruturado, cujo roteiro de questões foi construído pelas autoras, abordando aspectos relacionados aos objetivos do trabalho, tais como o momento da descoberta da lesbianidade e as reações e sentimentos decorrentes disso, as possíveis conseqüências positivas e negativas de assumir essa orientação sexual, o manejo dessa condição pelas entrevistadas, a reação dos familiares diante da revelação da sua orientação sexual, etc. As entrevistas foram realizadas individualmente, com duração média de 20 minutos, sendo gravadas e transcritas de forma fidedigna, para posterior análise dos dados. Das seis entrevistas realizadas, quatro ocorreram na própria universidade e as outras duas na residência das participantes, por escolha delas.

Cabe salientar que a coleta das informações só teve início após a leitura e a assinatura do Termo de Consentimento Livre e Esclarecido pela participante, com o esclarecimento das dúvidas, quando solicitado, e do preenchimento de uma Ficha de Dados Demográficos. Também é importante esclarecer que, previamente ao início da coleta de dados, foi realizada uma entrevista-piloto, com a finalidade de verificar a pertinência do roteiro de perguntas em relação aos objetivos do trabalho.

\section{RESULTADOS E DISCUSSÃO}

Os dados coletados através das entrevistas semiestruturadas foram submetidos à análise de conteúdo proposta por Bardin (1977). De acordo com essa proposta, a análise ocorreu em três diferentes fases. Na primeira delas, a pré-análise, a fase de organização propriamente dita, objetivou-se tornar operacionais e sistematizar as idéias iniciais, conduzindo a um esquema do desenvolvimento das operações, num plano de análise. Posteriormente a essa fase ocorreu a exploração do material, que consistiu em operações de codificação, desconto ou enumeração do material. $\mathrm{O}$ tratamento dos resultados obtidos e a interpretação aconteceram na terceira fase, na qual os resultados brutos foram tratados de maneira a adquirirem significados e se tornarem válidos, realizando-se inferências e interpretações.

A partir da análise das entrevistas foram criadas diversas categorias e subcategorias temáticas, apresentadas a seguir. Depois se encontra a descrição de cada categoria com suas respectivas subcategorias, ilustradas por falas das participantes e discutidas tendo por base a literatura revisada.

A primeira categoria englobou todos os depoimentos das participantes que se referiram ao Momento/situação da descoberta da homossexualidade. Foram encontradas quatro subcategorias: atração por mulheres ("Olha, teve, daquilo que eu sentia quando criança, um momento específico que eu soube que era atração por mulher, aí pelos 14, 15 anos, que eu descobri. No colégio, com colegas, assim, que eu vi que era aquilo que eu queria, que era daquilo que eu gostava", P4); sem atração por homens ("Desde os meus oito anos, quando comecei a me reconhecer como gente, eu já percebi, assim, que eu era diferente, tipo, eu já não sentia atração por homens, entendeu? Já pensava só em negócio de brincar com guris, com bola e tudo", P1); decepção pelo sexo masculino ("Quando me decepcionei totalmente com homens, são uns cavalos”, P2); e não teve momento/situação específica ("Na verdade eu sempre tive interesse desde criança, eu sempre tive curiosidade”, $\mathrm{P} 3$ ).

Os achados do presente estudo concordam com as idéias de Sullivan (1996), que refere serem comuns entre homossexuais femininas os casos em que não há uma opção pela homossexualidade, mas sim, um processo de reconhecimento e enfrentamento de algo que já é inerente ao indivíduo. De fato, Fairchild e Hayward (1996) pontuam que muitas mulheres se percebem diferentes desde a infância, mas só se definem e se consideram homossexuais quando sentem atração sexual por outras mulheres. Nesse sentido, as participantes referiram a homossexualidade não como uma opção, mas sim como algo inerente à sua pessoa e à sua história, que foi se revelando naturalmente, a partir da percepção de diferenças em relação a amigas e colegas.

Fairchild e Hayward (1996) também assinalaram que a maioria dos homossexuais vivencia relacionamentos heterossexuais antes de se definir 
sexualmente, o que também ficou evidente no presente estudo, pois, das seis participantes, quatro referiram experiências heterossexuais prévias à descoberta da homossexualidade. Dessas, duas chegaram a casar e ter filhos, separando-se após algum tempo.

Uma das participantes referiu ter descoberto seu interesse por mulheres ao se decepcionar com os homens. Tal achado parece concordar com a afirmação de Mott (1987), para quem os relacionamentos entre mulheres caracterizam-se por níveis profundos de comunicação, ternura, carinho e delicadeza, aspectos esses buscados e não encontrados por ela na sua relação heterossexual.

Na segunda categoria, Sentimentos em relação à descoberta, emergiram quatro subcategorias temáticas, a partir da análise da fala das participantes: normalidade ("Foi normal, a coisa mais simples na minha vida, não teve nenhum... assim..., eu não me senti ruim, ou, porque às vezes as pessoas dizem que tu perde o chão, né, mas pra mim não, foi uma coisa normal que aconteceu", P3); estranhamento ("No começo foi bem estranho, porque, como a gente era amiga, a gente tava sempre junto, eu sabia que ela ficava com outras mulheres, eu nunca tinha ficado, então não se passava isso pela minha cabeça no começo", P2); culpa ("No início foi complicado, eu cheguei a pensar nisso muitas vezes, perdi sono. Muitas vezes eu dizia pra mim: 'Isso não tá certo, não é assim, não pode, não dá", P5); e confusão ( "No início eu não sabia o que fazer, porque eu não sabia pra onde ir, se eu contava pra minha família, se eu não contava, o que eu fazia, então eu fui guardando isso", P6).

Tais sentimentos negativos (estranhamento, culpa e confusão) apresentados pelas participantes diante da descoberta da homossexualidade concordam com a literatura revisada, especialmente com o estudo citado por Garcia (2003), realizado em Florianópolis - SC, com dez mulheres que mantinham prática sexual com outras mulheres, no qual $60 \%$ delas referiram a sensação de estar fazendo algo errado, apesar de considerarem a experiência prazerosa.

No entanto, o fato de duas participantes referirem como "normais" os sentimentos diante da descoberta da homossexualidade contraria os achados teóricos, que apontam uma dificuldade de aceitação e de tranqüilidade quanto à questão (Trevisan, 2002). Assim, esse achado pode estar refletindo uma mudança de mitos e crenças pessoais e sociais em relação à homossexualidade feminina, o que pode amenizar os sentimentos de culpa e anormalidade enfrentados por algumas dessas mulheres; ou, como se trata de um relato retrospectivo, as emoções sentidas pelas entrevistadas no momento da descoberta podem ter sido ressignificadas em função de suas vivências posteriores, perdendo o caráter negativo inicial.

Interessante observar que os sentimentos das participantes quanto à descoberta da homossexualidade apareceram associados aos achados da primeira categoria, pois para aquelas que já percebiam seus desejos homossexuais desde a infância (P1, P3), a descoberta foi encarada com naturalidade/normalidade.

A categoria três, referente às Conseqüências positivas trazidas pela homossexualidade, foi composta pelas subcategorias felicidade ("A minha felicidade, eu acho pra mim isso é o mais importante", P1); maior qualidade no relacionamento ("Me trouxe felicidade, companheirismo, uma pessoa que tu pode contar sempre”, P5); possibilidade de relacionamento com ambos os sexos ("Talvez essa coisa de tu poder ficar com pessoas do mesmo sexo e do sexo oposto, não, claro, sendo uma pessoa promíscua, mas tu podendo até analisar o que tu prefere, se realmente é aquilo”, P4); e novas amizades ("Conheci pessoas também homossexuais que são maravilhosas, muitas amizades, muitos contatos", P6).

Pensa-se que um posicionamento mais autêntico por parte das participantes a respeito de sua orientação homossexual pode implicar uma nova postura diante do relacionamento afetivo, considerando-o mais satisfatório, na medida em que a mulher está conseguindo realizar seus verdadeiros anseios, sem culpa e repressão. Daí pode também decorrer o sentimento de felicidade citado pelas participantes. Nesse sentido, Fairchild e Hayward (1996) apontam que a maioria dos homossexuais reprime seus sentimentos na tentativa de se moldar à sociedade. Quando não há mais a repressão, os sentimentos são expostos e a felicidade vem ao encontro dessa liberdade e satisfação com a orientação sexual.

Quanto à conquista de novas amizades, aspecto referido por uma participante, pode-se pensar que muitos homossexuais, pela questão do preconceito, acabam estabelecendo trocas sociais somente entre homossexuais. Assim, a participante teve oportunidade de firmar amizades que não teria construído se não se definisse dessa forma e passasse a frequientar novos ambientes.

Já na quarta categoria, Conseqüências negativas trazidas pela homossexualidade, emergiram como subcategorias: o preconceito ("Tem certos momentos que é complicado, que as pessoas notam que tu é um pouco diferente, que teu jeito é um pouco diferente, de repente ficam com alguma piadinha, com alguma 
coisinha", P4); e o isolamento ("Ah, isso acontece, né, por causa do preconceito, isso aí é muito complicado, não é aberto a todos esse tipo de coisa, então a gente vive num meio bem fechado", P3). Algumas participantes também não referiram nenhuma conseqüência negativa ("Pra mim não tem nada negativo, tá tudo ótimo”, P1).

Lacerda, Pereira e Camino (2002) ressaltam que o preconceito pode ser considerado como uma frustração reprimida e deslocada para grupos mais fracos, o desenvolvimento de um tipo de personalidade arbitrária, com pouca disposição à abertura mental. O sujeito, então, seria reconhecido como anistórico, ou seja, apresentando práticas e comportamentos não esperados para os gêneros masculino e feminino, tornando-se diferente e passível de preconceitos (Toneli \& Perucchi, 2006), por ser visto como uma subversão da ordem (heterossexualidade como norma; Anjos, 2000).

A fala das participantes caracterizou o preconceito como prejudicial para o relacionamento afetivo homossexual, limitando e restringindo ações não restritas ao público heterossexual, como as demonstrações de carinho, assim como os locais freqüentados pelas participantes. Nesse sentido, o isolamento social foi mencionado, indicando a existência de lugares freqüentados apenas pelo público homossexual, o que reforça a segregação entre as diferentes orientações sexuais, promovendo a manutenção da exclusão social e a invisibilidade lésbica (Mesquita, 2004). O fato de uma participante não ter mencionado nenhuma conseqüência negativa pode estar representando uma facilidade sua para lidar com a sua orientação sexual, que foi descoberta já na infância, tendo se revelado de uma forma natural e ainda contando com o apoio da família.

As categorias que seguem fizeram referência específica aos aspectos familiares e suas repercussões para as participantes. Na categoria cinco, Reação inicial da família frente à revelação da homossexualidade, foram agrupados todos os depoimentos acerca da reação dos familiares à descoberta da orientação homossexual da filha. Emergiram as subcategorias: apoio ("Foram boas, ótimas, me apoiaram, acham que é o melhor pra mim, que eu que tenho que decidir, foi ótimo! Eu achei que ia ser diferente, tinha medo", P1); nervosismo ("No começo ela riu, acho que ela ficou nervosa", P2); choque ("Na verdade ela não teve reação, ela ficou quieta, ela disse que já imaginava por causa das minhas amigas e tal", P3; "Olha, ela ficou um pouco assustada, meio sem saber o que me dizer", P4); agressividade ("Escutei muitas coisas deles horríveis.
Tentei me expressar, só que não conseguia. Foi bem ruim, muito cruel", P5); e culpa ("A primeira coisa foi ela começar a chorar, e a primeira coisa que ela disse, eu lembro até hoje, foi 'Onde foi que eu errei?", P6).

A grande maioria das respostas apontou para reações negativas por parte dos familiares diante da descoberta da orientação sexual das participantes. Mott (1987) enfatiza que poucas famílias aceitam e convivem bem com membros de orientação sexual homossexual, estando mais presentes a intolerância e o inconformismo. $\mathrm{O}$ autor ainda comenta que, para a grande maioria das lésbicas, a família acaba por se constituir, na maioria das vezes, uma das principais preocupações, como repressora ou como cobradora de compromissos heterossexuais. Os achados do presente estudo corroboram parcialmente essas afirmações, concordando ainda com as idéias trazidas por Fairchild e Hayward (1996), que apontam que as expectativas geradas pelos pais, relacionadas a casamento e netos, e os sentimentos de culpa, são fatores importantes que permeiam a questão da descoberta da homossexualidade dos filhos.

Somente uma participante comentou ter recebido apoio da família no momento da revelação. Apesar de pouco expressivo, esse depoimento pode estar expressando um avanço social, no sentido de maior visibilidade e aceitação da homossexualidade, a partir da desarticulação de mitos e crenças preconceituosas. Mas, como ocorre com toda mudança, essa também parece estar acontecendo de forma gradual, uma vez que a maioria das famílias, segundo a percepção das participantes, apresentou dificuldades em lidar com o fato. Nesse sentido, interessante observar que essa participante referiu ter tido suas expectativas contrariadas pela reação positiva dos familiares, o que não foi referido pelas demais participantes, que já esperavam reações negativas, achado que corrobora a literatura, em que se menciona que os filhos têm medo da rejeição dos familiares no momento da revelação (Fairchild \& Hayward, 1996). Para essas autoras, a revelação aos familiares seria o último passo dentro do processo de auto-aceitação, idéia também referida por Marvin e Miller (2002).

Já a sexta categoria, Sentimentos ante a reação dos familiares à revelação, foi composta pelas subcategorias: felicidade ("Me senti feliz, me senti bem, porque eu imaginei que ela ia enlouquecer, ficar doente, mas não, numa boa, ficou até feliz, assim... que eu tava bem, que eu tava namorando já tinha um tempo; ficou feliz, tudo de bom", P1); acolhimento ("Me senti bem, pois eu pude falar pra ela e não tive nenhuma rejeição em relação a isso", $\mathrm{P} 4)$; 
infelicidade ("Eu fiquei mais mal do que eu já tava", P6); e confusão ("Eu não sabia o que fazer, fiquei muito perdida”, P5).

A confusão referida pelas participantes pode estar relacionada ao fato de a reação da família ter sido muito mais negativa do que o esperado, colocando em dúvida até mesmo sua orientação homossexual. Por outro lado, a infelicidade pareceu expressar a frustração de expectativas positivas das participantes no caso, de uma reação mais favorável por parte dos familiares. Tais achados relacionam-se com os da categoria anterior e os confirmam, quando se comentou sobre as expectativas negativas dos filhos quanto à reação dos familiares. Interessante ressaltar o depoimento da participante 4 , que referiu ter se sentido acolhida, embora também tenha referido uma reação familiar categorizada como choque. Nesse caso, pode-se pensar que para ela o choque foi considerado melhor do que uma reação negativa de xingamento, ofensa ou até violência física e/ou psicológica por parte dos familiares. Contudo, também não se pode desconsiderar que a participante não tenha sido clara ou fidedigna no seu depoimento.

Por outro lado, alguns indivíduos esperam receber o apoio da família e muitas vezes não é isso o que acontece, despertando sentimentos de infelicidade, como referido pelas participantes. Nesse ponto, cabe comentar as idéias de Goldfried e Goldfried (2001) sobre a necessidade de apoio e aceitação por parte da família na busca de qualidade de vida de gays e lésbicas. À medida que estes sentem que continuam sendo amados e protegidos pela família, os problemas sociais trazidos pela homossexualidade acabam sendo menos difíceis de enfrentar. Isso fica exemplificado pelo depoimento de felicidade da participante 1 , que exemplifica o medo da rejeição recém-mencionado e a surpresa diante de uma reação familiar positiva, não confirmando sua expectativa.

A sétima e última categoria, intitulada Forma atual de a família lidar com a homossexualidade, englobou as seguintes subcategorias temáticas: normalidade ("Normal, como um casal hétero. Eles lidam com a gente, minha mãe gosta muito dela, trata como uma filha; normal", P1); tranqüilidade ("Tá supertranqüilo, assim... eu acho que tá cada vez melhor. Ela me diz que sofre um pouco ainda com isso, mas a gente tá conversando e eu vejo que cada vez mais ela tá se soltando. Supertranqüilo”, P6); e negação ("Sabe quando a pessoa meio que apaga, esquece a situação, assim? Foi o que ela fez, assim, ela bloqueou, eu acho, tá fazendo de conta que não tá existindo, apesar de que, de vez em quando, ela comenta alguma coisa e tal”, P3).
Strommen, citado por Goldfried e Goldfried (2001), enfatizou que os pais passariam por diferentes fases no seu processo de aceitação da homossexualidade dos filhos, sendo que a última delas, após a superação do luto pela identidade heterossexual do/a filho/a, seria a aceitação completa, sendo ele/a quem é e da forma que é. Assim, algumas famílias do presente estudo, a partir da percepção das participantes, parecem estar alcançando esse estágio, o que é um achado bastante positivo.

Cabe lembrar que a postura de duas famílias se modificou desde o momento da descoberta até a atualidade, havendo uma mudança na forma de lidar com essa questão, tendo em vista possivelmente as influências históricas, sociais e culturais sobre a questão da homossexualidade, que situaram esse fenômeno de diferentes formas ao longo do tempo, demonstrando sua construção histórica (Lacerda , et al., 2002; Miranda, 2001; Mott, 1987).

Não obstante, nem todos os familiares parecem estar conseguindo atingir o estágio referido acima, pois três participantes ainda enfrentavam sentimentos de negação por parte deles. Nessa perspectiva, Sanders (1994) comenta que os convites para a autoanulação são oferecidos às lésbicas a partir de variadas fontes. A família de origem opera, na maior parte das vezes, a partir de uma crença de que todos os filhos serão heterossexuais e crescerão seguindo estilos de vida e experiências heterossexuais, apresentando dificuldade para reformulá-la.

Os achados também corroboram parcialmente as idéias de Goldfried e Goldfried (2001), que afirmam que o primeiro passo da família seria reconhecer e aceitar o fato de o filho/a ser homossexual, sendo esse um processo que requer tempo, envolvendo a reorganização de expectativas e valores. Contudo, a negação apresentada pelas famílias de três participantes (P3, P4 e P5) impede o reconhecimento de sua orientação homossexual. Apenas a ruptura desse processo provocará uma confrontação com a realidade e possibilitará o início da aceitação por parte da família.

Por outro lado, nem sempre esse processo ocorre de forma espontânea, sendo necessária talvez uma intervenção psicológica no sentido de expandir a visão da sociedade e, conseqüentemente, das famílias, para a importância da aceitação e do apoio aos seus membros nas diferentes formas de relacionamentos afetivosexuais e arranjos familiares existentes na atualidade.

\section{CONSIDERAÇÕES FINAIS}

A partir dos resultados encontrados, pode-se constatar que, para a maioria das participantes, a 
lesbianidade foi vista como uma condição promotora de felicidade, sendo considerada algo normal/natural. Contudo, a existência de preconceitos persiste como uma situação negativa ligada à lesbianidade. De modo geral, o estudo também detectou que as entrevistadas estavam satisfeitas com o seu relacionamento homossexual, que foi percebido como mais harmonioso e completo em comparação ao heterossexual. Na percepção das participantes, os familiares em geral reagiram de forma negativa à descoberta da sua orientação sexual. Em alguns casos, houve melhoras na postura da família quanto à questão no decorrer do tempo, mas alguns familiares ainda persistiam negando a situação até o momento da realização do estudo. Seus sentimentos diante da reação dos familiares variaram conforme a atitude apresentada pela família, de maior ou menor aceitação.

Acredita-se que conhecer a forma como a lésbica e seus familiares lidam com a sua orientação sexual permitiu levantar algumas necessidades a serem contempladas a partir da criação de programas psicossociais voltados para essa parcela da população, tais como o oferecimento de um suporte psicológico não apenas para essas mulheres, mas também para seus familiares, que podem apresentar reações negativas, sofrimento e desorganização em face da questão. Em decorrência, homossexuais femininas poderiam sentir-se mais tranqüilas para vivenciar mais plenamente suas experiências afetivo-sexuais.

De todo modo, em função das mudanças sociais atuais e do fato de o presente estudo não pretender esgotar o assunto, pensa-se que novas pesquisas sobre o tema no contexto nacional devam ser realizadas, examinando de modo mais detalhado o funcionamento e a dinâmica desses relacionamentos afetivos. Além disso, pensa-se que as vivências de filhos de casais homossexuais femininos também poderiam ser melhor investigadas, por fazerem referência à homoparentalidade, tema bastante em voga nos dias de hoje nas esferas jurídica, sociológica e antropológica.

\section{REFERÊNCIAS}

Anjos, G. (2000). Identidade sexual e identidade de gênero: subversões e permanências. Sociologias, 1(4), 274-305.

Bardin, L. (1977). Análise de conteúdo. Lisboa: Editora 70.

Borges, L. S. (2005). Visibilidade lésbica: um comentário a partir de textos da mídia. Sexualidade, Gênero e Sociedade, edição especial (23, 24, 25), 20-21.

Fairchild, B., \& Hayward, N (1996). Agora que você já sabe: o que todo pai e toda mãe deveriam saber sobre a homossexualidade. Rio de Janeiro: Record.
Ferreira, R. C. (2007). O gay no ambiente de trabalho: análise dos efeitos de ser gay nas organizações contemporâneas. Dissertação de Mestrado, Universidade de Brasília, Brasília. Recuperado em 15 de dezembro, 2007, de http://www.unb.br/face/ppga/arquivos/dissertacoes

Freud, S. (1976). Três ensaios sobre a teoria da sexualidade. Em Edição Standard Brasileira das Obras Psicológicas Completas de Sigmund Freud (Vol. 6, pp. 115-230). Rio de Janeiro: Imago. (Original publicado em 1905).

Freud, S. (2007). Conferências introdutórias sobre psicanálise. Conferências I, XVI a XXVIII (pp. 1-144). Recuperado em 25 de dezembro, 2007, de http://www.fafich.ufmg.br/ verlaine/ freudconferencias.pdf (Original publicado em 1917).

Garcia, O. R. Z. (2003). Prática sexual entre mulheres: identidade ou pluralidade sexual? Cadernos de Pesquisa Interdisciplinar em Ciências Humanas, 1(56), 1-20.

Góis, J. B. H. (2003). Desencontros: as relações entre os estudos sobre a homossexualidade e os estudos de gênero no Brasil. Estudos Feministas, 11(1), 289-297.

Goldfried, M. R., \& Goldfried, A. P. (2001). The importance of parental support in the lives of gays, lesbian and bisexual individuals. Psychotherapy in Pratice, 57(5), 681-693.

Heilborn, M. L. (1992). Vida a dois: conjugalidade igualitária e identidade sexual. Em Anais do VIII Encontro Nacional de Estudos Populacionais (Vol. 2, pp. 143-156). Recuperado em 15 de dezembro, 2007, de http://www.sistema.clam.org.br/ biblioteca/files

Lacerda, M., Pereira, C., \& Camino, L. (2002). Um estudo sobre as formas de preconceito contra homossexuais na perspectiva das representações sociais. Psicologia: Reflexão e Crítica, 15(1), 165-178.

Laurenti, R. (1984). Homossexualismo e a Classificação Internacional de Doenças. Revista de Saúde Pública, 18(5). Recuperado em 15 de dezembro, 2007, de http://www.scielo.com.br

Marvin, C., \& Miller, D. (2002). Os casais de lésbicas na entrada do século XXI. Em P. Papp (Org.), Casais em Perigo: novas diretrizes para terapeutas (pp. 269-294). Porto Alegre: Artmed.

Matias, D. (2007). Psicologia e orientação sexual: realidades em transformação. Análise Psicológica, 1(25), 149-152.

Mesquita, M. (2004). Movimento de mulheres lésbicas no Brasil: sinalizando algumas conquistas e desafios para o século XX. Recuperado em 26 de dezembro, 2007, de http://www.comuniles.org.br/index.php?option=com_content\& task $=$ view\&id $=35 \&$ Itemid $=39$

Miranda, S. de A. (2001). Amor entre mulheres: um estudo sócioantropológico das relações afetivas entre pessoas do sexo feminino. Monografia de Graduação, Universidade de Fortaleza, Fortaleza. Recuperado em 11 de abril, 2006, de http://www.armariox.com.br/conteudos/cienciaepesquisa.php

Mott, L. (1987). O lesbianismo no Brasil. Porto Alegre: Mercado Aberto.

Mott, L. (2001). História da homossexualidade no Brasil: cronologia dos principais destaques. Em X Encontro Brasileiro de Gays, Lésbicas e Transgêneros, Maceió, 25-10-2001. Recuperado em 26 de dezembro, 2007, de http://www.ggb.org.br/cronologia_movimento_homossexual.ht $\mathrm{ml}$ 
Mott, L. (2003). O jovem homossexual: noções básicas de direitos humanos para professores, professoras e adolescentes gays, lésbicas e transgêneros. Revista do Mestrado em Educação, 7, 95-102.

Sanders, G. (1994). O amor que ousa declarar seu nome: do segredo à revelação nas afiliações de gays e lésbicas. Em E. Imber-Black (Org.), Os segredos na família e na terapia familiar (pp. 219244). Porto Alegre: Artes Médicas.

Sullivan, A. (1996). Praticamente normal: uma discussão sobre o homossexualismo. São Paulo: Companhia das Letras.

Toneli, M. J. F., \& Perucchi, J. (2006). Territorialidade homoerótica: apontamentos para os estudos de gênero. Psicologia e Sociedade, 18(3), 39-47.
Torrão Filho, A. (2005). Uma questão de gênero: onde o masculino e o feminino se cruzam. Cadernos Pagu, 24, 127-152.

Trevisan, J. S. (2002). Devassos no paraíso: a homossexualidade no Brasil, da colônia à atualidade ( $5^{\mathrm{a}}$ ed.). Rio de Janeiro: Record.

Victora, C., \& Knauth, D. R. (2004). Corpo, gênero e saúde: a contribuição da antropologia. Em M. N. Strey \& S. T. L. Cabeda (Orgs.), Corpos e subjetividade em exercício interdisciplinar (pp. 81-91). Porto Alegre: EDIPUCRS.

Recebido em 02/06/2007

Aceito em 07/12/2007

Endereço para correspondência : Yáskara Arrial Palma. Rua Ernesto Marsiaj, 743/205. Bairro Petrópolis, CEP 95070-530, Caxias do Sul-RS. E-mail: yaskarapalma@yahoo.com.br 